\title{
A busca domiciliar em decorrência da prisão em flagrante
}

The household search as a result of prison in flagrant

\author{
Edelmo Oliveira Nunes \\ Academia de Polícia Militar de Brasília \\ Leandro Rodrigues Doroteu \\ Universidade de Brasília. \\ JacQues NogueIra AraúJo \\ Academia de Polícia Militar de Brasília, APMB, brasil. \\ Sônia Marise Salles Carvalho \\ Universidade Federal de Brasília.
}

Resumo De acordo com a Constituição vigente, a casa é asilo inviolável do indivíduo, preceito esse que poderá ser relativizado em caso de flagrante delito. Existem no desenrolar do serviço policial ocasiões em que a prisão ocorre em ambiente diverso do domicílio e se faz necessária a busca domiciliar com o intuito de se produzir as provas e se firmar a caracterização do crime. Nesse caso, o delito não aconteceu no domicílio do autor, portanto, não está explícito que a autoridade policial poderá adentrar o asilo inviolável do indivíduo. A Constituição Federal assevera ainda que o acesso poderá se dar mediante consentimento do morador. Ocorre que, durante a prisão em flagrante, pode-se inferir que tal autorização tenha se dado mediante coação, em função da própria natureza da atividade policial. Para tanto, seria conveniente que, em caso de flagrante, a figura do consentimento não estivesse obrigatoriamente presente, a fim de dar maior amplitude ao serviço policial. O objetivo deste trabalho é delimitar até que ponto poderá ser realizada a busca e apreensão domiciliar em decorrência da prisão em flagrante ocorrida fora do domicílio.

Palavras-chave: Domicílio. Flagrante. Provas. Garantias. Busca Domiciliar. 
Abstract According to the current Constitution, the house is inviolable asylum of the individual, a precept that can be relativized in case of flagrante delicto. In the course of the police service, there are occasions when the arrest takes place in an environment other than the home and it is necessary to search the domicile with the purpose of producing the evidence and establishing the characterization of the crime. In this case, the offense did not occur in the author's home, so it is not explicit that the police authority can enter the inviolable asylum of the individual. The Federal Constitution further asserts that access may be granted with the consent of the resident. It occurs that during the arrest in flagrante it can be inferred that this authorization has been given through coercion, due to the very nature of the police activity. For this, it would be advisable that in case of flagrante the figure of the consent was not necessarily present, in order to give greater scope to the police service. The objective of the present study is to determine the extent to which the search and seizure can be carried out as a result of the arrest in the offense occurred outside the home.

Key-words: Domicile. Flagrant. Evidences. Warranties. Home SeARCH.

\section{INTRODUÇÃO}

Este trabalho trata da busca domiciliar, sem consentimento, em decorrência da prisão em flagrante. Será analisado se simultaneamente à prisão em flagrante poderá ser efetuada a busca domiciliar e se essa busca depende ou não do consentimento do preso e dos demais moradores da residência. Inicialmente, teremos como hipóteses se durante a prisão em flagrante a busca domiciliar poderá ser feita somente mediante o consentimento do preso ou dos demais moradores. Outra hipótese é que a situação de flagrância autoriza a busca, independentemente de consentimento.

Tal abordagem se justifica devido ao fato de os elementos de prova serem de extrema importância para a manutenção da prisão, bem como, da sua conversão em prisão preventiva e, na fase processual, de uma pos- 
sível condenação. No entanto, os elementos de prova são de difícil produção. Observa-se que no momento da prisão, ou seja, no calor dos acontecimentos é que são produzidos os principais e mais relevantes meios de prova do cometimento de um crime. Em função desse fato, faz-se necessário saber com clareza se durante a prisão em flagrante os condutores da prisão podem ou não efetuar a busca domiciliar e se esta depende ou não do consentimento do preso ou dos demais moradores da residência.

Para nortearmos o presente trabalho teremos como objetivo, entre outros, definir direitos e garantias fundamentais; delimitar a extensão e o conceito de "casa, asilo inviolável do indivíduo" e analisar a prisão em flagrante e suas particularidades, bem como, a manutenção e a perda de direitos fundamentais ocasionados por ela.

Quanto aos objetivos, trata-se de uma pesquisa exploratória, onde seu escopo é buscar a solução legal e fática quando das ações policiais. Quanto aos procedimentos técnicos, será uma pesquisa bibliográfica, pois terá como base livros, leis, julgados, e outros trabalhos científicos que se referem ao assunto em estudo. $\mathrm{O}$ trabalho foi dividido nas seguintes seções: Direitos e Garantias Fundamentais; O Asilo Inviolável do Indivíduo; Os Direitos Fundamentais e a Prisão em Flagrante; e a Violação de Domicílio e a Prisão em Flagrante e as Considerações Finais.

\section{Direitos e garantias FUndamentais}

A atuação policial requer o fiel cumprimento a todos os mandamentos contidos no ordenamento jurídico do Estado. Tal ordenamento tem como base primeira sua Constituição, que é a lei maior de um país. $\mathrm{O}$ Brasil, constituído em Estado Democrático de Direito, tem na Constituição da República Federativa do Brasil (CRFB), promulgada em 1988, todos os fundamentos de onde derivam todas as demais leis e normas, permanecendo esta em um patamar de supremacia sobre todas as outras.

Além de dar o direcionamento a todas essas demais normas, a CRFB confere a um título especial atenção, justamente onde estão insculpidos os direitos e garantias fundamentais. Dada a sua importância, 
sua inobservância deve ser tratada com rigor, ensejando a atuação do poder de punir do Estado. Vejamos então a definição de Dantas:

[...] a Constituição pode ser definida, em sua acepção jurídica, como a norma jurídica fundamental, que condiciona a edição, interpretação e validade das normas infraconstitucionais, e que tem por conteúdo o conjunto de normas (princípios e regras) que fornecem a organização fundamental de ente estatal, além de fixar os direitos e garantias fundamentais, bem como os direitos sociais e econômicos (DANTAS, 2009, p. 19).

Observa-se que em primeiro plano estão os direitos e garantias fundamentais, que na verdade são uma forma de derivação dos direitos humanos universais. Sem essas garantias não há que se falar em estado democrático de direito, por isso são de fundamental importância para a própria existência dos seres humanos. Portanto, para que se tenha uma autorização de restrição de um direito fundamental se faz necessário que seja algo em mesmo nível de importância e que esteja claramente estabelecido legalmente, ou seja, qualquer tipo de exceção somente poderá ser tolerado em situações excepcionais e que sirva também para que o estado democrático de direito seja preservado, em função dos demais cidadãos, pela própria manutenção da lei e da ordem. Nesse sentido é o que lesiona Haberle (2002) citado por Nery Junior e Nery, (2014, p. 226):

Os direitos fundamentais constituem, na atualidade, conceito que engloba os direitos humanos universais e os direitos nacionais dos cidadãos garantidos pela Constituição, contra os abusos que possam ser cometidos pelo Estado ou pelos particulares. Ambas as classes de direitos são, ainda que com intensidade diferente, parte integrante necessária da cultura jurídica de todo Estado Constitucional.

É importante frisar novamente que, em decorrência do que foi explanado, pode-se afirmar que não há direitos absolutos, até mesmo os 
fundamentais. Embora não se possa admitir que a quebra desses direitos seja feita de forma corriqueira e banal. Esses direitos são definidos como fundamentais porque são o sustentáculo da própria vida em sociedade, que ao longo de sua evolução não mais pôde permitir que o poder soberano e absoluto do governante prevalecesse sobre a existência do homem ou mesmo a respeito deste sobre o mais fraco. Assevera Nelson Nery (2014, p. 226):

A regra é a prevalência dos direitos e garantias fundamentais contra o interesse público e particular e contra os interesses do Estado. De outra parte, não existem direitos absolutos, de sorte que mesmo os direitos fundamentais podem sofrer mitigação. A exceção, portanto, é a mitigação dos direitos e garantias fundamentais. Essa mitigação, entretanto, somente pode ocorrer em situações excepcionalíssimas, mediante ponderação pelo princípio da proporcionalidade. Não se pode fazer da exceção regra e banalizar essa excepcionalidade, tangendo direitos fundamentais ao argumento de que o interesse público deve prevalecer sobre eles.

No Artigo $5^{\circ}$. da CRFB estão estabelecidos os direitos e deveres individuais e coletivos, sendo essa a principal fonte de direitos e garantias fundamentais do ordenamento jurídico pátrio. É nesse dispositivo constitucional que se encontra o objeto de estudo do presente trabalho. Inicialmente, vejamos o inciso que define a particularidade inerente ao que se deve garantir quando se refere à casa: "XI - a casa é asilo inviolável do indivíduo, ninguém nela podendo penetrar sem consentimento do morador, salvo em caso de flagrante delito ou desastre, ou para prestar socorro, ou, durante o dia, por determinação judicial" (BRASIL, 1988).

Nesse diapasão, cabe ressaltar que o flagrante delito, objeto de estudo do presente trabalho, não é o citado no inciso mencionado. O objeto é o flagrante delito ocorrido fora do ambiente definido como casa nos casos em que como decorrência dessa prisão a busca domiciliar poderá ou não ocorrer e se esta depende do livre consentimento do morador. 


\section{O ASILO INVIOLÁVEL DO INDIVÍDUO}

Com efeito, Silva (2008) e Canotilho (2010) concordam que a íntima conexão da garantia da inviolabilidade do domicílio com a esfera da vida privada e familiar lhe assegura um lugar de honra na esfera dos assim chamados direitos da integridade pessoal. E por tal razão, a proteção do domicílio foi, ainda que nem sempre da mesma forma e na atual amplitude, um dos primeiros direitos assegurados no plano das declarações de direitos e dos primeiros catálogos constitucionais.

A proteção contra ordens gerais de buscas domiciliares já constava da Declaração dos Direitos do Homem da Virgínia, de 1776. Diversos documentos históricos pelo mundo reiteram a importância de tal proteção. A qual foi prevista na Carta Imperial Brasileira de 1824, onde se falava na casa como asilo inviolável do indivíduo. De lá para cá o direito à inviolabilidade do domicílio passou a ser presença constante nos catálogos constitucionais de direitos fundamentais e mesmo do direito internacional dos direitos humanos.

O que cabe enfatizar é que também na tradição constitucional brasileira, como se verá logo adiante, o direito fundamental à inviolabilidade do domicílio ocupa lugar de destaque entre os direitos fundamentais que dizem respeito à proteção da vida pessoal e familiar de um modo geral. Guardando, de resto, íntima conexão com outros direitos fundamentais, como é o caso da proibição do aproveitamento de provas ilícitas. Dessa forma, o âmbito de proteção do direito fundamental (inviolabilidade do domicílio) e os limites de atuação da autoridade policial serão objetos de estudos neste trabalho.

Diante de tamanha importância, o conceito de domicílio no ordenamento jurídico brasileiro buscou dar a maior amplitude possível, com vistas a garantir a fundamental necessidade que tem o indivíduo de existir em seu convívio social e os protegendo das mazelas daqueles que detêm o poder, seja esse estatal ou particular. Ao retratar o asilo do indivíduo como casa, este estando definido no inciso XI Artigo $5^{\circ}$. da CF, o legislador está se referindo a qualquer tipo de recinto em que o cidadão deve manter a sua segurança e intimidade preservados, seja individualmente 
ou de sua família ou quem quer que seja que ali se estabeleça. Como bem descreve Rogério Tucci (2011, p. 338): "Qualquer lugar, enfim - complementamos -, em que despontada a privacidade, se encontre, permanente ou transitoriamente, determinada coisa ou pessoa".

Com o mesmo viés, o próprio Artigo $5^{\circ}$. da CF preocupou-se em enumerar, de forma taxativa, quais as ocasiões em que poderão ocorrer os ingressos lícitos no domicílio, são elas: "XI - [...] em caso de flagrante delito ou desastre, ou para prestar socorro, ou, durante o dia, por determinação judicial”. Observa-se que as situações enumeradas estão em um patamar legal que visa à própria segurança e existência das pessoas que ali residem e da coletividade como um todo. Portanto, sendo tais motivos bastantes para figurarem como exceção à fundamental garantia dada pela CRFB. A taxatividade imposta pela CF é ratificada pelas lições de Rogério Tucci (2011, p. 338): "Só mesmo nos casos em que a própria Constituição Federal ressalva ela é permitida, até porque a relevância das situações (flagrante delito, desastre ou necessidade de prestação de socorro) importa na sua prevalência sobre a privacidade tutelada”. Em alguns casos, o flagrante delito ocorrido fora da residência depende de coleta de provas ou apreensão de objetos relacionados ao crime no interior da residência do preso.

\section{Os DIREITOS FUNDAMENTAIS E A PRISÃo EM FLAGRANTE}

É natural que para a convivência em sociedade padrões e limites sejam estabelecidos para que os anseios e vontades pessoais não extrapolem os direitos dos demais indivíduos. Com esse intuito nascem as normas legais, visando à regulação das atitudes das pessoas em detrimento do contexto do homem como ser social. Diante da complexidade das relações sociais, as leis e normas vão surgindo e se ramificando de acordo com a evolução e as necessidades da citada regulação, tendo como parâmetro fundamental uma lei maior de onde irá derivar todas as demais normas. Com esse objetivo, nasce a Constituição Federal como Carta Magna do arcabouço jurídico do Estado, onde serão insculpidos todos os princípios e fundamentos para a construção das demais nor- 
mas, assim como bem assevera Nery Júnior e Nery (2014): "Constituição significa ordem jurídica fundamental do Estado e da sociedade".

Todavia, a convivência social deve seguir seu curso normal, de modo que as leis e normas devem ser invocadas somente por ocasião dos conflitos de vontades e interesses, mediando e disciplinando as condutas dos cidadãos. Diante da diversidade dos mencionados conflitos e vontades, o direito, no decorrer dos tempos, se ramificou e se especializou em vários ramos, de acordo com as necessidades sociais. Destarte, o Direito Penal surge com o objetivo de disciplinar e garantir os bens jurídicos de maior relevância no desenrolar da atividade social, de modo que esse ramo somente será acionado quando da ineficácia de todos os demais, haja vista que ele deve ser considerado como a ultima ratio (última razão, último recurso) do direito a ser invocado. Caracterizando o princípio da intervenção mínima do Estado, também chamado, ou seja, o Direito Penal se presta a tutelar somente bens jurídicos de alta lesividade, onde outro ramo do direito não se mostrou eficaz. Para ilustrar, cabe frisar as lições de Rogério Greco (2016, p. 3):

Se é com base nesse princípio que os bens são selecionados para permanecer sob a tutela do Direito Penal, porque considerados como os de maior importância, também será com fundamento nele que o legislador, atento às mutações da sociedade, que com a sua evolução deixa de dar importância a bens que, no passado, eram de maior relevância, fará retirar do nosso ordenamento jurídico-penal certos tipos incriminadores.

Como ramo do direito dos bens jurídicos mais valorosos, ao Direito Penal se presta, por consequência, o direito de punir do Estado, o jus puniendi, que se traduz na aplicação de sanção quando do descumprimento de mandamento legal. Os tipos de sansões penais encontram-se enumerados no Artigo 32 do Código Penal, podendo tais penas ser privativas de liberdade, restritivas de direito e de multa, sendo as primeiras aplicadas aos casos mais graves e mediante a prisão daquele que comete a infração penal. Já a prisão, de acordo com o inciso LXI do Artigo 
$5^{\circ}$. da CF, somente se opera em duas situações: por meio de mandado emanado de juiz ou em flagrante delito, ressalvadas as questões relacionadas aos militares.

Como bem explica Capez: "O termo flagrante provém do latim flagare, que significa queimar, arder. É o crime que ainda queima, isto é, que está sendo cometido ou acabou de sê-lo" (CAPEZ, 2010, p. 307). Cabe frisar novamente que a prisão em flagrante é a única que não decorre de ordem judicial, motivo pelo qual os elementos de prova devem ser consistentes o bastante para que ela não seja de pronto relaxada. Por isso, seria de suma importância que em determinadas situações da prisão em flagrante a casa do infrator fosse submetida a uma busca. A seguir, vejamos o que o Artigo $5^{\circ}$. da Constituição traz relacionado à garantia fundamental por ocasião da prisão em flagrante:

LXI - ninguém será preso senão em flagrante delito ou por ordem escrita e fundamentada de autoridade judiciária competente, salvo nos casos de transgressão militar ou crime propriamente militar, definidos em lei;

LXII - a prisão de qualquer pessoa e o local onde se encontre serão comunicados imediatamente ao juiz competente e à família do preso ou à pessoa por ele indicada;

LXIII - o preso será informado de seus direitos, entre os quais o de permanecer calado, sendo-lhe assegurada a assistência da família e de advogado;

LXIV - o preso tem direito à identificação dos responsáveis por sua prisão ou por seu interrogatório policial; LXV - a prisão ilegal será imediatamente relaxada pela autoridade judiciária (BRASIL, 1988).

Observa-se que o constituinte teve o cuidado de delimitar quais os direitos inerentes ao preso, mesmo estando privado de seu principal direito, que é o direito de ir e vir. Por sua vez, deve-se ressaltar que o direito à inviolabilidade de domicílio e as garantias conferidas ao preso estão instituídos no mesmo artigo da Constituição da República, o que nos leva a deduzir que estão no mesmo nível de importância, cabendo ainda inferir 
que tal observação terá grande importância quando do imbróglio da busca domiciliar na casa do elemento preso em flagrante delito.

O Artigo 302 do Código de Processo Penal (CPP) enumera as situações nas quais se opera a prisão em flagrante:

Artigo 302. Considera-se em flagrante delito quem:

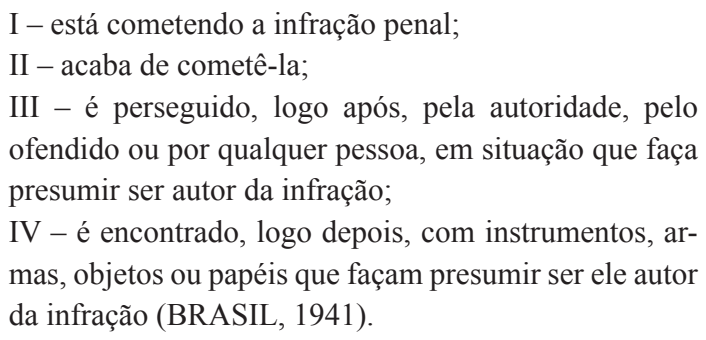

A situação que se tem como parâmetro para o presente estudo se refere ao fato de ocorrer a prisão em flagrante de um indivíduo, sem que este esteja em seu ambiente domiciliar e se tenha a suspeita, fundamentada, de que outros elementos e provas relacionados com o crime estejam no domicílio do infrator. $\mathrm{O}$ artigo citado contempla as várias ocasiões em que se opera o flagrante, mas não contempla diretamente o caso da busca domiciliar que porventura se tenha a necessidade de se proceder após a prisão, com o intuito de se colher elementos de prova ou novas circunstâncias do crime.

O exemplo considerado como exponente para o estudo ora em construção é o caso de a pessoa abordada na via pública com quantia razoável de substância entorpecente e se tem como fundada suspeita que os demais elementos que levarão a tipificar aquela ação como tráfico de substâncias entorpecentes se encontra no interior de sua residência, como caderno de controle de clientes, balança de precisão ou mesmo dinheiro produto do crime. Outro caso clássico é o autor de um homicídio preso na via pública logo após a consumação, mas que, no entanto, antes de sua prisão, este foi até a sua casa e ocultou a arma do crime. 
Diante dos exemplos mencionados, traz-se à baila o inciso IV do Artigo 302 do CPP. Quando o legislador afirma estar caracterizado o flagrante estando o suposto autor com instrumentos, armas ou objetos que façam presumir ser o autor do delito, infere-se que faz alusão ao objeto que esteja em sua posse. Portanto, a princípio não faz menção ao autor que foi visto entrando em casa para ocultar esses objetos e posteriormente foi devidamente preso em função de outras circunstâncias e se nesse caso poderia o responsável pela prisão proceder à busca domiciliar com o intuito de se obter as provas relativas ao crime. Poderia ainda se estender ao tipificado no inciso III, ou seja, ser perseguido logo após em situação que faça presumir ser o autor. No caso em análise, o autor já se encontra preso, mas faltam elementos. Sobre o caso do flagrante impróprio já descrito, vejamos o que diz Capez (2010, p. 308):

\footnotetext{
No caso do flagrante impróprio, a expressão "logo após" não tem o mesmo rigor do inciso precedente (acaba de cometê-la). Admite um intervalo de tempo maior entre a prática do delito, a apuração dos fatos e o início da perseguição. Assim, "logo após" compreende todo o espaço de tempo necessário para a polícia chegar ao local, colher as provas elucidadoras da ocorrência do delito e dar início à perseguição do autor.
}

Como visto, fala-se em colher provas e depois perseguir o autor. No entanto, não está se referindo à assertiva inversa, ou seja, prender o autor para depois colher as provas.

\section{A ViOLAÇão de dOMicílio E A PRISÃo EM FLAGRANTE}

O Artigo 150 do Código Penal Brasileiro (CP) tipifica o crime de violação de domicílio e em seu parágrafo segundo caracteriza como caso de aumento de pena o fato cometido por funcionário público, fora dos casos legais, ou com inobservância das formalidades estabelecidas em lei, ou com abuso de poder. Damásio de Jesus (2004) em seu Código Penal Anotado faz referência à entrada do funcionário público na casa 
para cumprimento de certas diligências, citando a penhora, o sequestro e a busca e apreensão, asseverando ainda que devem ser realizadas mediante princípios previstos em lei, mas não discorre sobre a contenda em que ora se estuda.

No caso das Polícias Militares, a violação de domicílio está tipificada no Artigo 226 do Código Penal Militar (CPM), em ambos os códigos o mencionado crime tem idênticos enunciados, pena máxima e qualificadora. No entanto, no parágrafo $2^{\circ}$. do citado artigo, ao mencionar os casos de agravação de pena, especifica entre as possibilidades o fato cometido por militar em serviço. Portanto, vislumbra-se que caso ocorra a busca domiciliar sem que haja amparo legal para a sua realização, estes estariam sujeitos às penas previstas no citado artigo do CPM, estando ainda tais penas sujeitas à respectiva agravação. Diante desse fato, é evidente que a busca domiciliar em decorrência da prisão em flagrante somente deve ocorrer se for afastada a possibilidade do cometimento do crime de violação de domicílio (BRASIL, 1969).

Ao mencionar o cometimento do crime de violação de domicílio, tipificado no Artigo 226 do CPM, deve-se neste ínterim fazer um parêntese em relação ao cometimento de Abuso de Autoridade, em conformidade com o instituído pela Lei ${ }^{\circ}$. 4.898, de 9 de dezembro de 1965. Existe um conflito aparente de normas em decorrência do Artigo $3^{\circ}$., letra "b" da citada lei: "Art. $3^{\circ}$. Constitui abuso de autoridade qualquer atentado: b) à inviolabilidade de domicílio". Observa-se tal conflito em função de que quando da agravação da pena, o $\S 2^{\circ}$. do Artigo 226 do CPM nos remete ao fato cometido por militar em serviço. No nosso caso em estudo, tendo efetuado a prisão em flagrante, estaria o policial em serviço, ou mesmo em razão desta, portanto abarcado pela agravante mencionada. No entanto, a Lei $n^{\circ} .4 .898$ é específica para a aplicação ao detentores de poder estatal, desse modo, sendo direcionada, e de forma específica, aos policiais, e outros agentes públicos no exercício de suas funções (BRASIL, 1969).

Diante do conflito ora suscitado, é natural que o agente público observe quais serão as consequências decorrentes de sua ação, caso venha incidir em desacordo com qualquer mandamento legal. No caso 
em tela, normalmente quando vem à tona a aplicação da lei de abuso de autoridade, o agente público abstrai a pena principal e se preocupa ordinariamente com a pena acessória, que é a constante da letra "c" do $\S 3^{\circ}$. do Artigo $6^{\circ}$., que consiste na perda do cargo.

No caso de policiais militares regidos pela legislação penal militar e a legislação penal extravagante (abuso de autoridade), parte da doutrina invoca o princípio da especialidade. Por ser direcionada especificamente para os agentes públicos e detentores de poder, boa parte da literatura assevera que deve ser aplicada a esses casos a Lei $n^{\circ} .4 .898 / 65$, mesmo cometidos por policiais militares em serviço. No entanto, Neves e Streifinger (2014, p. 1.140), na busca para resolver a contenda, invocam o critério da sucessão temporal, tendo como solução a aplicação do código penal especial:

Ademais, deve-se lembrar que o CPM e a Lei n.4.898/65, nos tipos em conflito, possuem elementos especializantes intensos, não sendo esse critério seguro para a solução do conflito aparente de normas; deve-se valer do critério da sucessão temporal das leis penais, frisando-se que a Lei de Abuso de Autoridade surgiu em 1965, enquanto o Código Penal Castrense, em 1969, já tendo este como conteúdo informativo aquela lei, concluindo-se que, mesmo conhecendo o delito de abuso de autoridade, o legislador penal militar desejou desconstituí-lo como autônomo, colocando-o como majorante de outro crime.

Com o intuito de dar a guarida necessária ao exercício da prisão em flagrante e da respectiva busca domiciliar posterior à prisão praticada por policias militares, busca-se respaldo no parágrafo $3^{\circ}$. do mesmo Artigo 226 do CPM, cujo teor é o mesmo do Artigo 150 do Código Penal comum. $\mathrm{O}$ mencionado parágrafo traz à baila as possibilidades de exclusão do crime, enumerando em dois incisos as respectivas situações onde não estará presente a violação de domicílio. No inciso I as ocasiões em que não estará configurado o crime durante o dia, que são 
elas: para efetuar a prisão ou outra diligência; o inciso em tela traz ainda que para tais situações deverão ser observadas as formalidades legais e ainda em cumprimento de lei ou regulamento militar. Portanto, da leitura desse inciso nos remete, ao mencionar o período diurno, a prisão efetuada mediante mandado judicial e ao cumprimento de algum tipo de busca ou apreensão, também realizada mediante ordem ou autorização judicial, assim como leciona Rogério Greco (2016, p. 483):

A primeira hipótese diz respeito ao cumprimento de determinação judicial, seja para efetuar prisão de alguém ou mesmo para realizar outra diligência, a exemplo do cumprimento de mandado de busca e apreensão. Nesses casos, somente poderá ser cumprida a ordem judicial durante o dia.

Já o inciso II remete à prisão em flagrante, tendo em vista que se refere ao caso de alguma infração penal que esteja sendo ali praticada ou na iminência de o ser, independentemente do horário em que esteja ocorrendo. Dessa maneira, o parágrafo $3^{\circ}$. do citado Artigo 226 do CPM, especificamente em seu inciso II, dá a guarida necessária para que seja efetuada a prisão em flagrante de crimes que estejam sendo cometidos no interior de qualquer domicílio. No entanto, no caso específico do presente trabalho, nos referimos ao adentramento no domicílio do autor de um crime que teve a sua prisão em flagrante efetuada em outro local, ou seja, o crime não foi praticado na "casa" do autor (BRASIL, 1969).

Destarte, o $\S 3^{\circ}$. em comento não possibilita sustentabilidade para que seja realizado busca domiciliar na casa do infrator, após este ter sido preso em flagrante delito em local diverso de seu domicílio. Para esse dispositivo, merece ainda frisar a ressalva lembrada por Alves-Marreiros, Rocha e Freitas (2015), de que por força de lei ou regulamento somente se estes repetirem o constante do inciso XI do Artigo $5^{\circ}$. da Carta Magna de 1988, sendo outra hipótese inaceitável, de modo que lei ou regulamento não poderá autorizar a violação de domicílio para efetuar a prisão ou outro tipo de diligência. 
No entanto, da interpretação do já citado inciso II do $\S 3^{\circ}$., ao mencionar que não se constituirá crime a entrada em casa alheia quando algum crime está sendo ali praticado, infere-se que em caso de crimes que são praticados de forma contínua ou permanente, sendo parte ou um desses atos praticados no interior da residência, depara-se com um caso onde poderá ser efetuada busca domiciliar, mesmo sem o consentimento do infrator ou dos moradores. Os crimes classificados como crimes de ação continuada e sua definição encontram-se insculpidos no Artigo 71 do $\mathrm{CP}$ :

\section{Crime continuado}

Artigo 71 - Quando o agente, mediante mais de uma ação ou omissão, pratica dois ou mais crimes da mesma espécie e, pelas condições de tempo, lugar, maneira de execução e outras semelhantes, devem os subsequentes ser havidos como continuação do primeiro, aplica-se-lhe a pena de um só dos crimes, se idênticas, ou a mais grave, se diversas, aumentada, em qualquer caso, de um sexto a dois terços (BRASIL, 1940).

Nesse sentido, o Supremo Tribunal Federal, quando do julgamento pela Segunda Turma, do Habeas Corpus $n^{\circ}$. 121.419, de relatoria do Ministro Ricardo Lewandowski, prolatou acórdão no sentido de que no caso de crime permanente não há que se falar em inviolabilidade de domicílio ou prova obtida de forma ilegal pela ausência de mandado de busca e apreensão lavrado por juiz:

3. Consoante o entendimento da Corte, "[é] dispensável o mandado de busca e apreensão quando se trata de flagrante de crime permanente, podendo-se realizar as medidas sem que se fale em ilicitude das provas obtidas" (RHC no. 121.419/SP, Segunda Turma, Relator o Ministro Ricardo Lewandowski, DJe de 17/10/14).

Em julgamento análogo, o STJ firmou entendimento de que: 
A garantia constitucional da inviolabilidade do domicílio cede espaço nos casos de flagrante delito, não merecendo censura a ação policial intentada com o objetivo de efetuar prisão no interior de residência, após constatar em campana a realização de comércio ilícito de entorpecentes (STJ, RHC 7.749, Rel. Vicente Leal, $6^{\mathrm{a}}$ T., DJU 28/9/1988).

Em uma decisão mais recente, datada de 18 de abril de 2017, decidiu o STF em julgamento realizado pela Segunda Turma segundo a qual "policial só pode entrar na casa de alguém se tiver mandado judicial de busca e apreensão ou se houver fundadas razões de que ocorre flagrante delito no local". No julgamento do Habeas Corpus $\mathrm{n}^{\circ}$. 138.565, relator Ministro Ricardo Lewandowski pode se observar o reforço do mesmo posicionamento já citado do STF em uma decisão da mesma turma três anos mais tarde (RHC no. 138.565/SP, Segunda Turma, Relator o Ministro Ricardo Lewandowski, DJe de 18/04/17).

Diante dos julgados e das doutrinas citadas, conduz-se a afirmar que não é possível uma interpretação extensiva do dispositivo constitucional na busca e apreensão com violação de domicílio. Em qualquer hipótese que a medida é tomada sem o amparo constitucional, é medida ilegal que macula a prisão e a produção probatória gerando consequências processuais. Em um dos casos, se trata da apreensão de arma de fogo, onde um dos autores de um crime indicou aos policiais o local onde se encontravam as armas, fato que sucedeu a pedido com alegação de prova obtida por meio ilícito, sendo então denegado o pedido pelo fato de que a posse de arma já constitui crime no caso absorvido por uma conduta mais grave. No outro caso, tratava-se de tráfico de entorpecentes, onde após constatação do crime por meio de campana, foi realizado busca domiciliar e a respectiva prisão e, da mesma forma, após alegação de ilegalidade por conta da violação de domicílio, denegou-se o pedido, mas o crime estava ocorrendo no interior da residência. E no último caso, também envolvendo tráfico de drogas, os policiais invadiram o domicílio sem ordem judicial e sem a caracterização prévia do flagrante, situação que maculou o ato repercutindo na legalidade da prisão e da produção probatória. 


\section{CONSIDERAÇÕES FINAIS}

Este artigo teve como proposta realizar uma análise da busca domiciliar, sem consentimento, em decorrência da prisão em flagrante. Onde foi analisado se simultaneamente à prisão em flagrante poderia ou não ser efetuada a busca domiciliar e se essa busca depende ou não do consentimento do preso e dos demais moradores da residência.

Inicialmente, tivemos como hipóteses se durante a prisão em flagrante a busca domiciliar poderia ser realizada somente mediante o consentimento do preso e dos demais moradores, ou se essa busca poderia ocorrer independentemente de consentimento.

Para norte do trabalho, teve como objetivo definir direitos e garantias fundamentais; delimitar a extensão e o conceito de "casa, asilo inviolável do indivíduo" e analisar a prisão em flagrante e suas particularidades, bem como, a manutenção e a perda de direitos fundamentais ocasionados por ela. Ao final, pode-se afirmar que a inviolabilidade de domicílio somente será desrespeitada nos casos citados na Constituição Federal, tendo apenas como casos extensivos da prisão em flagrante os crimes permanentes e os crimes de ação continuada.

Constatou-se que a atuação policial como órgão estatal garantidor da lei e da ordem, quando a serviço em um estado democrático de direito, faz que suas ações estejam em um lapso tão estreito e qualquer deslize estará sujeito ao crivo mais severo da lei. No jargão policial diz-se que a atuação "é no fio da navalha", de um lado a omissão, do outro o excesso, ambos podem configurar crimes.

Portanto, quando o assunto é inviolabilidade de domicílio, deve-se lembrar que estamos tratando de um direito fundamental construído ao longo do tempo. Tempos esses onde os indivíduos, nem mesmo em casa, possuíam a tão merecida tranquilidade do lar, um estado individual de segurança jurídica.

São evidentes que, no afã da guerra do combate ao crime, fossem ampliadas as possibilidades de atuação relacionadas com a violação de domicílio, e se abriria o leque de prisões e apreensões, mas estaríamos em contrapartida banalizando um princípio constitucional tão basilar, 
que somente com essa medida estaríamos abandonando o estado democrático de direito. Todavia, ao ser permitida a entrada em domicílio mediante consenso ou sem recusa, já é medida bastante a proporcionar uma atuação suficiente da polícia.

Como sugestões para futuros estudos, deve-se analisar o próprio consentimento, sua forma de coleta, e os possíveis limites entre um constrangimento ilegal no momento de sua obtenção. Também foi constatada uma lacuna nos limites do exercício da busca em relação aos cômodos, como fazer a busca somente nos aposentos do preso e áreas em comum. E por último, é interessante pesquisar, à luz do ordenamento jurídico, que a busca, mesmo em situações de flagrante delito, autoriza a captura de imagens por parte dos agentes públicos e sua posterior divulgação.

\section{REFERÊNCIAS}

ALVES-MARREIROS, Adriano; ROCHA, Guilherme e FREITAS, Ricardo. Direito Penal Militar. São Paulo: Método, 2015.

BRASIL. Constituição (1988). Constituição da República Federativa do Brasil de 1988: promulgada em 5 de outubro de 1988. Contém as emendas constitucionais posteriores. Brasília, DF: Senado, 1988.

. Código Penal. Decreto-lei 2.848, de 07 de dezembro de 1940. Disponível em: http://www.planalto.gov.br/ccivil 03/decreto-lei/Del2848compilado.htm. Acesso em: $1^{\circ}$. nov. 2016.

. Código Penal Militar. Decreto-lei 1.001, de 21 de outubro de 1969.

Disponível em: https://www.planalto.gov.br/ccivil 03/decreto-lei/Del1001. htm. Acesso em: 11 dez. 2016.

. Código de Processo Penal. Decreto-lei 3.689, de 03 de outubro de 1941. Disponível em: http://www.planalto.gov.br/ccivil 03/decreto-lei/ Del3689.htm. Acesso em: 3 nov. 2016.

. Lei 4.898 de 09 de Dezembro de 1965. Regula o Direito de Representação e o processo de Responsabilidade Administrativa Civil e Penal, nos casos de abuso de autoridade. Disponível em: http://www.planalto.gov. br/ccivil_03/leis/L4898.htm. Acesso em: 11 dez. 2016. 
CANOTILHO, José Joaquim Gomes. Direito Constitucional e Teoria da Constituição. Coimbra: Almedina, 2010.

CAPEZ, Fernando. Curso de Processo Penal. São Paulo: Saraiva, 2010.

DANTAS, Paulo Roberto de Figueiredo. Direito Processual Constitucional. São Paulo: Atlas, 2009.

GRECO, Rogério. Código Penal Comentado, 10. ed. Rio de Janeiro: Impetus, 2016.

JESUS, Damásio E. Código Penal Anotado, 15. ed. São Paulo: Saraiva, 2004.

NERY JUNIOR, Nelson e NERY, Rosa Maria de Andrade. Constituição Federal Comentada e Legislação Constitucional, 5. ed. São Paulo: Revista dos Tribunais, 2014.

NEVES, Cícero Robson Coimbra e STREIFIGER, Marcello. Manual de Direito Penal Militar, 4. ed. São Paulo: Saraiva, 2014.

SILVA, José Afonso da. Curso de Direito Constitucional Positivo, 30. ed. São Paulo: Malheiros, 2008.

TUCCI, Rogério Lauria. Direitos e Garantias Individuais no Processo Penal Brasileiro, 4. ed. São Paulo: Revista dos Tribunais, 2011.

\section{SOBRE OS AUTORES}

\section{Edelmo Oliveira Nunes}

Possui o Curso de Formação de Oficiais pela Academia de Polícia Militar de Brasília. Especialista em Gestão de Segurança Pública pelo ISCP e Especialista em Gestão Estratégica de Segurança pelo UNIS.

E-mail: leandrodoroteu@hotmail.com

\section{Leandro Rodrigues Doroteu}

Mestrando em Administração pela Universidade de Brasília. Professor do Centro Universitário Projeção (UniPROJEÇÃO) Mestre em Linguística (UNIFRAN) e em Ciências Policiais de Segurança e Ordem Pública (CAES). Especialista em Direito Público, Docência do Ensino Superior e Direito Empre- 
sarial. Tem graduação em Curso de Formação de Oficiais pela APM PMDF, graduação em Direito e Letras.

CV: http://lattes.cnpq.br/8206060991226658

E-mail: doroteu.leandro@gmail.com

\section{Jacques Nogueira AraúJo}

Mestre em Direitos Humanos, Cidadania e Violência na área de Ciência Política pela UNIEURO-DF; Especialista em Segurança Pública pelo Centro de Educação da Polícia Militar do Estado da Paraíba; Especialista em Ciências Jurídicas pela Universidade Cruzeiro do Sul; Bacharel em Ciências Contábeis pela Universidade Paulista - UNIP; Curso de Formação de Oficiais pela APMB.

CV: http://lattes.cnpq.br/2658293190798917

E-mail: jacquesaraujo7@gmail.com

\section{Sônia Marise Salles Carvalho}

Doutora em Sociologia pela Programa de Pós-graduação do Departamento de Sociologia da Universidade Federal de Brasília/UnB (2008). Mestrado em Ciências Sociais pela Universidade Federal do Rio Grande do Norte (1991). Professora da Universidade Federal do Amazonas em exercício provisório na Universidade de Brasília-UnB. Pesquisadora na área de Sociologia do Trabalho e Sociologia Clínica. Pesquisadora do campo da Economia Solidária no Brasil. Coordenadora da Incubadora de Tecnologia Social e Inovação no Centro de Apoio ao Desenvolvimento Tecnológico da Universidade de Brasília. Diretora Executiva da Rede Interuniversitária de Estudos e Pesquisas sobre o Mundo do Trabalho/UNITRABALHO. Membro da Associação de Pesquisadores de Economia Solidaria/ABPES.

CV: http://lattes.cnpq.br/7582726565531671

E-mail: smarises@yahoo.com.br

Submetido em: 23-2-2018

Aceito em: 14-6-2018 